\title{
Los cambios acontecidos en las funciones de la comunicación y en el valor de la información
}

\author{
Manuel MARTIN SERRANO
}

REFERENCIA PARA LAS CITAS DE ESTA PUBLICACIÓN Y DE SUS CONTENIDOS:

MARTIN SERRANO, Manuel (1992): "Los cambios acontecidos en las funciones de la comunicación y en el valor de la información”, Reis (Revista Española de Investigaciones Sociológicas), no 57, pp. 13-20. Disponible en:

http://www.reis.cis.es/REISWeb/PDF/REIS 057 04.pdf

Recuperado el_de de 2 de http://eprints.ucm.es/13240/

\section{UTILIZACIÓN DE ESTE DEPÓSITO:}

Usted es libre de copiar, distribuir y comunicar públicamente la obra bajo las siguientes condiciones, que corresponden a la licencia Creative Commons que protege este texto:

Reconocimiento. Debe reconocer y citar al autor original, utilizando la "REFERENCIA PARA LAS CITAS DE ESTA PUBLICACION Y DE SUS CONTENIDOS" (véase recuadro superior).

No comercial. No puede utilizar esta obra para fines comerciales.

Sin obras derivadas. No se puede alterar, transformar, o generar una obra derivada a partir de esta obra. 


\title{
Reading LA PRODUCCIÓN SOCIAL DE COMUNICACIÓN. LA COMUNICACIÓN PÚBLICA EN EL CAMBIO DEL MUNDO
}

\author{
Presentación y estudio documental por Daniel Franco Romo
}

En E-Prints se tiene acceso a una selección de la obra original de Manuel Martín Serrano (véase: "Publicaciones de Manuel Martín Serrano disponibles en E-Prints. Selección sistematizada"*, en http://eprints.ucm.es/11107/).

Una parte importante de dicha obra está dedicada al estudio de LA PRODUCCIÓN SOCIAL DE COMUNICACIÓN. La producción social de comunicación (Madrid: Alianza, 1986, 1993, 2004) es un libro que integra teoría, metodología e investigación y con el que Manuel Martín Serrano contribuye decisivamente a que la comunicación forme parte de las ciencias sociales. Esta obra ofrece una perspectiva y una sistemática específicas, para investigar las relaciones entre sociedad y comunicación. Introduce, como un componente necesario para el análisis de los cambios históricos de las sociedades, las sucesivas transformaciones de la comunicación pública, en sus diversos niveles: transformaciones de las tecnologías, de las organizaciones que tienen a su cargo la labor de proveer de información a la colectividad, y de los usos que de todo ello se hace en cada comunidad. La producción social de comunicación es un título de referencia en la bibliografía científica de la comunicación. Su influencia se refleja en el acervo de publicaciones que se han distanciado de la "teoría de la comunicación social" para trabajar con el enfoque de una "teoría social de la comunicación". Es evidente el giro que representa este cambio semántico.

En este Reading, se han seleccionado textos que corresponden a los tres niveles en los que se mueve esta parte de la obra del autor: el teórico, el de los usos sociales de la comunicación, el de los desarrollos metodológicos.

\section{Creación de la Teoría Social de la Comunicación}

Manuel Martín Serrano escribe que la producción social de comunicación es una actividad sociohistórica que requiere enfoques macrosociológicos. En consecuencia, propone e inicia la Teoría Social de la Comunicación. Está descrita en "Presentación de la Teoría Social de la Comunicación" (http://eprints.ucm.es/13237/). Los cambios que se están produciendo en el uso y en el valor de la información requieren este desarrollo teórico. El estudio de por qué y cómo hay que llevar a cabo esa renovación teórica está en uno de los artículos más esclarecedores del autor: "La epistemología de la comunicación a los cuarenta años de su nacimiento" (http://eprints.ucm.es/13238/).

\section{Orígenes y características de los usos actuales de la comunicación pública}

Cuando Manuel Martín Serrano elabora la Teoría Social de la Comunicación, ya había investigado y publicado sobre los formas históricas de producir comunicación pública y sus usos sociales, desde la Modernidad hasta la época actual. El tránsito desde la comunicación en la sociedad postindustrial a la comunicación en la emergente sociedad globalizada se describe en La mediación social (Madrid: Akal, 1977, 2008). Entre los escritos en los que se ha referido a ese tránsito, se ha seleccionado "Las transformaciones sociales vinculadas a la era audiovisual" (http://eprints.ucm.es/13187/) y "La ampliación de la realidad en la que vivimos con otro universo virtual" (http://eprints.ucm.es/11069/).

A comienzos de los años 80, anticipa que "La nueva era no va a ser de la comunicación, sino la de la conexión" (http://eprints.ucm.es/11065/). El autor reanaliza en clave de economía política las transformaciones en la producción comunicativa, tal como se puede apreciar en "Cuándo el valor de cambio de la información puede ser medido" (http://eprints.ucm.es/11067/). Y, en clave prospectiva, muestra que los mismos factores que están ampliando las aplicaciones sociales de las tecnologías comunicativas, también tienen un enorme potencial de desorganización. El análisis de cómo se verá afectado el actual orden de monopolio globalizado está resumido en "La forma vigente de producir comunicación pública. Desarrollo y quiebra” (http://eprints.ucm.es/13239/). El artículo publicado en Reis "Los cambios acontecidos en las funciones de la comunicación y en el valor de la información" (este depósito) relaciona la revolución informático-comunicativa con las transformaciones históricas que están en curso. La utilización de las nuevas formas de producir comunicación acabará remodelando, a escala universal, las formas de acción social. 
Manuel Martín Serrano se ha referido en varias ocasiones a la naturaleza dual que es característica de la producción social de comunicación: innovadora y redundante, controladora y al tiempo liberadora. Cree que por primera vez existen capacidades para que pueda decantarse hacia el desarrollo de la creatividad y la autonomía individuales. Véase en el texto "La gran paradoja que presenta la evolución histórica de la comunicación pública" (http://eprints.ucm.es/11063/).

\section{La producción social de comunicación y el colonialismo cultural}

La comunicación pública ha contribuido y lo sigue haciendo al colonialismo, desde la época de los descubrimientos a la de la globalización. Manuel Martín Serrano indica que ese uso la convierte en un arma de guerra y en un procedimiento de explotación. El autor escribe con frecuencia artículos sobre este tema, desde la perspectiva teórica e histórica que distingue a su obra. "Orígenes históricos de los usos actuales de la comunicación pública" (http://eprints.ucm.es/13242/) regresa a la época en la que los movimientos religiosos inventaron "la comunicación social" (a finales del siglo XIX) como herramienta para la catequesis. El neocolonialismo se apropia ese mismo modelo manipulador y lo adapta para crear dependencia. Aclara el autor que "el colonialismo se convierte en neocolonialismo cuando logra integrar el comercio y la transculturización en una única red". En nuestra época de producción en masa de estereotipia, el neocolonialismo tiene a todas las naciones por su territorio. Produce "La comunicación que globaliza la pobreza cultural" (http://eprints.ucm.es/13244/). Empobrecimiento que lleva implícito la sustitución del recurso a cualquier lenguaje hablado por la acción: véase "Cuando la eliminación del idioma propio hace de «la acción» el modo de narrar único o principal” (http://eprints.ucm.es/13245/). Manuel Martín Serrano ha acuñado categorías para describir la forma en la que se produce esa destrucción de bienes intangibles, en "La comunicación pública y la supervivencia" (http://eprints.ucm.es/13246/). También se ha seleccionado un texto que contiene, en su brevedad, importantes enseñanzas para el estudio y el entendimiento de cómo funcionan esos mecanismos de sometimiento: "El colonialismo cultural se analiza investigando las relaciones entre acción y comunicación" (http://eprints.ucm.es/13247/). Explica que la desorganización de las instituciones productivas, familiares y políticas de una comunidad es condición necesaria para que la producción comunicativa que transculturiza quebrante los valores y transforme las costumbres.

\section{Metodologías y técnicas para investigar la producción social de comunicación}

Manuel Martín Serrano suele elaborar los modelos de investigación que se adecuan a los planteamientos teóricos que él mismo ha propuesto. Por ejemplo, crea en La producción social de comunicación los conocidos conceptos de "Mediación cognitiva y estructural" (http://eprints.ucm.es/13166/). Son desarrollos de la teoría de la mediación, para el estudio de la comunicación pública, que se acompañan en dicho libro de los correspondientes "Diseños para investigar la producción social de comunicación" (http://eprints.ucm.es/13147/). Se reproduce "Un protocolo para llevar a cabo estudios paradigmáticos de la producción social de comunicación" (http://eprints.ucm.es/13248/), que se viene utilizando ininterrumpidamente, por su autor y por otros muchos investigadores.

\section{REFERENCIAS para enlazar este documento con los que cita y con aquellos que le citan}

\section{- “Prólogo para La mediación social en la era de la globalización” (http://eprints.ucm.es/10651/)}

- "La comunicación NO es una alternativa autónoma respecto al sistema de producción y de reproducción social" (http://eprints.ucm.es/11049/)

- “Las tres formas de empleo de la comunicación” (http://eprints.ucm.es/11058/)

- "La gesta y la parábola en los relatos de la comunicación pública” (http://eprints.ucm.es/11061/)

- "Innovación tecnológica, cambio social y control social” (http://eprints.ucm.es/11064/)

- "Mitos y carencias" (http://eprints.ucm.es/11066/) 
- "La transferencia de la ejecución a la indicación en los comportamientos humanos" (http://eprints.ucm.es/13105/)

- “Las relaciones macrosociológicas entre acción y comunicación” (http://eprints.ucm.es/13107/)

- "La comunicación en la existencia de la humanidad y de sus sociedades" (http://eprints.ucm.es/13112/)

- "El modelo dialéctico de la comunicación" (http://eprints.ucm.es/13116/)

- “Para qué sirve estudiar Teoría de la Comunicación?” (http://eprints.ucm.es/13145/)

- “Dialéctica, comunicación, mediación” (http://eprints.ucm.es/13254/)

- “La Teoría de la Comunicación, la vida y la sociedad" (http://eprints.ucm.es/13109/)

- “CIESPAL y la humanización de la comunicación: Puente entre el estado de las ciencias y la práctica de la comunicación” (http://eprints.ucm.es/13183/).

*Esta selección y sistematización de publicaciones de Manuel Martín Serrano, así como los análisis que les acompañan, se basa principalmente en los estudios realizados por los especialistas que han participado en dos monográficos dedicados a la obra del autor: el primero editado por Anthropos y preparado por Esteban Mate y el segundo por Chasqui, coordinado por Francisco Bernete. También se han localizado y utilizado numerosas reseñas que están publicadas en otras revistas científicas. El investigador Daniel Franco Romo ha planificado y supervisado la ejecución de todo el proyecto. 


\section{LOS CAMBIOS ACONTECIDOS EN LAS FUNCIONES \\ DE LA COMUNICACION \\ Y EN EL VALOR DE LA INFORMACION}

\section{Manuel Martín Serrano}

Universidad Complutense de Madrid

Este número monográfico se edita cuando está cambiando cualitativamente el uso social que se hace de la información; transformación que se produce tanto en el ámbito privado como en el público. De hecho, se están redefiniendo el empleo y las funciones sociales de la comunicación. Ese proceso de transformación se inició hace apenas diez años, cuando las políticas encaminadas a salir de la crisis económica generaron el estímulo y los recursos necesarios para iniciar una reconversión informacional del sistema productivo.

Somos los testigos de un cambio que todavía está en curso, a consecuencia del cual una parte mucho más considerable de la organización social va a gestionarse por medio de la producción, la distribución y el consumo de información. La manifestación más aparente para el individuo de esa ocupación de los espacios y los tiempos sociales, por las prácticas comunicativas, se percibe cuando se usan los nuevos artilugios que comienzan a ser equipamiento habitual de los hogares: vídeos, antenas parabólicas, ordenadores personales.

Esos usos son nada más que manifestaciones privadas de una muy profunda transformación institucional de la comunicación. Tal vez fascinados por las dimensiones lúdicas de las nuevas opciones comunicativas se nos pase desapercibido el alcance histórico que tienen otros efectos, tanto más trascendentes cuanto menos observables. De ellos me ocupo en este artículo.

\section{Reis}




\section{EL CAMBIO DEL VALOR DE LA INFORMACION}

Las transformaciones en el uso de la información se manifiestan a distintos niveles de la prácticas sociales y producen muy variados efectos: de naturaleza cognitiva, axiológica, cultural, familiar, laboral, económica, política. Para proporcionar las coordenadas que sirvan de referencia en un escenario tan complejo, conviene anticipar cuál ha sido el cambio cualitativo en el manejo de la información que ha desencadenado transformaciones de tanta envergadura. A mi juicio, es el siguiente: por primera vez en la historia de la humanidad, se están dando las condiciones tecnológicas, económicas y políticas requeridas para que sea posible establecer el valor de la información.

El sistema de producción para el mercado ya opera con la información en su condición de otro bien de consumo, desde el momento en el que el valor de cambio de la información puede calcularse con criterios de costo y beneficio, como se hace con cualquier otro producto.

La información no ha perdido por ello la función que hasta ahora ha cumplido de ser un valor de uso destinado a la reproducción social; función que sigue siendo imprescindible para organizar la convivencia a nivel colectivo y privado. Lo que ha variado es que el sistema productivo se está apropiando de esa gestión. Hasta ahora los poderes del Estado se habían reservado cuidadosamente el control de la comunicación pública, oponiendo resistencia a que la información referida a temas en los que se ponen en juego intereses esenciales para preservar el bien común quedase a cargo del sector privado.

De hecho, la producción de la comunicación pública era una de las pocas actividades donde todavía no regían en toda su libertad los criterios de mercado. Esa situación está llegando a su fin; por lo que es previsible que se vea muy transformada la forma en la que en el futuro se satisfagan las necesidades sociales de comunicación. La comunicación ha llegado a constituirse en un componente estratégico de cualquier actividad relacionada con la producción y la reproducción social, precisamente porque constituye un nexo importante entre ambas funciones. Esa característica aparece desde el momento en el que la información es, al tiempo, cemento de la integración social y materia prima en la producción de bienes y servicios.

Para que la comunicación haya adquirido este estatuto se han requerido previamente determinados avances teóricos y algunas conquistas tecnológicas concretas, que mencionaré seguidamente. 


\section{LAS BASES TEORICAS DE LOS CAMBIOS EN EL USO Y EN LA FUNCION DE LA COMUNICACION}

He señalado que, por primera vez, la información ha llegado a ser producida y comercializada con los mismos criterios económicos que los demás bienes. Ahora se calcula el valor de la información con independencia de cuál sea su contenido, en función de las variaciones que se producen entre la oferta y la demanda de los productos comunicativos. Por ejemplo, para las empresas que ofertan al banco de datos de los videotex es indiferente acumular información sobre iglesias o casas de citas. Desde el punto de vista económico, sólo cuenta el espacio que ocupan en el banco, cualquiera que sea la diferencia de uso que haya entre ambas bases de datos. Al usuario se le van a facturar a un precio equivalente en función del tiempo de ocupación de una línea.

Lograr establecer la medida cuantitativa de la información ha sido la conquista más reciente de la forma de producción capitalista; y tal vez represente la culminación de su éxito histórico, a los cuatrocientos años de su ininterrumpida apropiación de las actividades naturales y sociales para incorporarlas al mercado.

El cálculo cuantitativo del valor de la información ya era posible hace cuarenta años a partir de la publicación de la obra de Shannon Teoría matemática de la comunicación. Permite comparar (en bits) la cantidad de información que requiere la producción y el acceso a cualesquiera bienes comunicativos; desde un poema de Lorca a un número de la guía telefónica.

Esa solución teórica para el cálculo del valor económico de la información era un paso necesario pero no suficiente. Para que esa unidad de precio de los productos comunicativos pudiese ser utilizada en la práctica comercial de forma generalizada, se requerían condiciones tecnológicas que han comenzado a darse en este momento, por primera vez en la historia de la humanidad; a las que me referiré seguidamente.

\section{LAS INNOVACIONES TECNOLOGICAS QUE PERMITEN LA GESTION ECONOMICA DE LA OFERTA Y DEL CONSUMO DE COMUNICACION}

Para que la gestión de la comunicación se plegase a la forma económica de los restantes bienes era imprescindible resolver dos dificultades tecnológicas:

1.-Que las modalidades expresivas de la información fuesen intercambiables entre sí. Este logro ya se ha alcanzado cuando el texto, el número, la voz, la imagen, han dejado de requerir canales alternativos para ser produ- 
cidos, distribuidos y procesados. Hasta hace muy poco existía una barrera tecnológica que establecía diferencias entre la información analógica y la digital; entre el producto audiovisual y el alfanumérico, etc... Tales dificultades están a punto de desaparecer. En el momento en el que la información pueda expresarse optativamente en cualquiera de esas modalidades, y cuando se pueda reconvertir un modo de expresión en cualquier otro, se habrá logrado la plena equiparabilidad económica entre los productos comunicativos. Esas circunstancias se alcanzarán cuando una palabra, escrita o hablada, se pueda reproducir y procesar como una imagen o como un número; y viceversa.

2. -Que se acoplasen todos los sistemas que operan con la información. Se requería integrar en una única red los equipos audiovisuales, informáticos y reprográficos permitiendo indistintamente la recepción, emisión y reproducción de mensajes, de manera optativa en soporte acústico, en pantalla o impreso. Una muestra todavía incipiente de este desarrollo tecnológico se tiene en la consola multimedia. Sistema que recibe (y graba) la llamada telefónica y el sonido transmitido en cualquier longitud de onda; que dispone de pantallas en las que dar presencia a cualquier imagen, sea recibida por un televisor, o por un circuito propio; generada por una videocámara o diseñada en ordenador. Imágenes que pueden ser alteradas antes de ser grabadas y conservadas en la memoria. La citada unidad incorpora una impresora láser, la cual, además de dar salida al texto que se ha procesado y a la imagen que se ha memorizado, actúa como fotocopiadora que imprime el fax, el fotograma enviado por teletexto, la imagen procedente del vídeo. El sistema cuenta con las correspondientes funciones emisoras.

\section{LAS TRANSFORMACIONES EN LAS FUNCIONES SOCIALES DE LA COMUNICACION}

Estamos habituados a que nuestra vida transcurra en espacios y tiempos distinguibles; a ocuparnos en tareas cuya finalidad es diferenciable. El trabajo y el descanso; la educación y el entretenimiento; la convivencia familiar y las relaciones de naturaleza pública han contado en las sociedades surgidas de las revoluciones burguesas con su sitio y con su momento. Estas divisiones se van a ir borrando progresivamente, porque las mismas tecnologías que utilizamos para la comunicación, las iremos empleando para trabajar, para aprender y para divertirnos. Las distinciones entre espacios domésticos, laborales, lúdicos, formativos, van a perder su razón de ser. El sentido de los cambios se orienta a que las tareas que ahora se desempeñan en ámbitos exteriores y en colectividad (por ejemplo, en la fábrica y la oficina), se incorporen a los espacios domésticos para ser desempeñadas en soledad. 
A la larga, van a perder significado distinciones existenciales entre las dimensiones personales y colectivas de la comunicación. Los canales por los que circula la información de carácter privado o público ya se están integrando. Un único sistema de comunicación ofrecerá un mismo equipamiento tecnológico que, optativamente, se va a utilizar como la puerta de entrada para la comunicación de masas (por ejemplo, cuando se vea un programa de televisión o se «lea» un periódico en pantalla), como el camino para la comunicación persona a persona (por ejemplo, cuando se establezca una teleconferencia o se transmita un fax) y como el instrumento para adquirir, organizar y utilizar la información (por ejemplo, cuando se conecte y se alimente una base de datos; cuando se controle la cuenta bancaria; se aprendan idiomas recurriendo al ordenador o al vídeo; se juegue a los marcianos).

Pero esa integración de los distintos usos de la información en un único sistema (informático-comunicacional) es sólo una fase de un proceso que tiene más alcance. Creo que son todas las actividades relacionadas con la reproducción social, las que comienzan ya a ser gestionadas en estrecha interdependencia con las actividades de producción social. Hay que enfrentarse con un mega-sistema que incluye estos tres componentes:

\section{(información - organización - acción)}

No es esta la ocasión de explicar las razones y las características de este acoplamiento. El lector interesado puede encontrar ese análisis en otros trabajos anteriores*. Ahora interesa subrayar lo siguiente:

La información está destinada a penetrar en el ámbito de todo lo programado $y$ de todo lo programable; es decir, en cada nivel natural o artificial, material o inmaterial, que sea susceptible de ser intervenido por el hombre. Este horizonte hace prever que la comunicación se va a ir refuncionalizando aceleradamente. La comunicación, tanto privada como pública, perdieron su condición de actividad autónoma desde su origen mismo; puesto que siempre se vieron implicadas en la producción y en la reproducción sociales. Ese proceso de control de la comunicación se ha hecho cada vez más elaborado y más amplio, al mismo ritmo en el que las sociedades devenían más complejas. Hasta ahora, la comunicación personal ha sido el modo principal mediante el que se producía y a través del que se operaba con la información. Desde ahora, no tiene porque seguir siendo necesariamente de esa manera. Usos sociales de la comunicación personal, referidos por ejemplo al entretenimiento, a la educación y a la coordinación del trabajo, pueden ya asegurarse sin la presencia física de un Alter. El programa, para

* Cf. del autor: La producción social de comunicación, Alianza Editorial, 1986, Madrid; Mitos y carencias, en «Comunicación Social 1989. Informe anual», Fundesco, Madrid, 1989; La epistemología de la comunicación a los cuarenta años de su nacimiento, «Rev. Telos», núm. 22, 1989. 
manejar los datos, puede ocupar en estos casos el lugar del diálogo. Desde el punto de vista de la eficacia, ese cambio puede suponer una mejora; pero se hace al costo de eliminar las funciones conativas y páticas de la comunicación personal; y nadie sabe qué consecuencias cognitivas, afectivas y de comportamiento van a desencadenarse cuando el ordenador sustituya al maestro, al camarada, al colega y al amigo, y también al enemigo.

Por lo que respecta a la comunicación pública, hasta ahora ha sido una actividad que no tenía precio, lo mismo que no se calculaba el costo de la solidaridad, o de la seguridad colectiva, o de la perpetuación de los valores y de las creencias. Aspectos estrechamente relacionados con el uso de la comunicación para satisfacer necesidades colectivas. Los Estados fueron progresivamente asumiendo la ejecución de esas funciones que eran socialmente imprescindibles, pero de escaso o nulo valor de cambio. He señalado que en el futuro es probable que ninguna función reproductiva de la comunicación pública siga siendo monopolio estatal. Lo mismo que se ha compartido la gestión de otros servicios públicos tan esenciales como la policía y el correo con empresas de seguridad y de courrier, se irá transfiriendo a las productoras de materiales comunicativos cada campo de la comunicación pública susceptible de proporcionar valores de cambio. No creo que queden exentos de ese traspaso al sector privado, ni la información relacionada con la salud ni con la política; ni con los festejos públicos, ni con los deberes y derechos ciudadanos, entre otras que ya están transferidas o a punto de serlo.

\section{UNA PENURIA TEORICA INDUCIDA, ACOMPAÑA A LA RADICAL TRANSFORMACION DE LAS POLITICAS COMUNICATIVAS}

Precisamente cuando mayor solidaridad va existiendo entre la producción de comunicación y la producción y reproducción social, los estudios macrosociológicos cada vez se realizan en menor cantidad. Desde el comienzo de la década de 1980 se inicia una inundación de estudios microsociológicos, centrados en investigar los efectos prácticos que en el consumo de información tiene la incorporación de tal o cual tecnología.

De hecho, las nuevas tecnologías de la comunicación han servido para sacar a la economía multinacional de la última crisis de sobreproducción y es inexorable que sean ellas las que generen la próxima crisis, todavía más grave y más larga que la precedente. Esos estudios de los efectos, parecen cada vez más vinculados con las políticas estatales de comunicación. Lo cual, en el actual contexto, significa que los estudios de la comunicación son parte o son otro aspecto de la planificación económica. Esa perspectiva instrumental se evidencia cuando se repasan los títulos de las investigaciones promovidas con financiación de los gobiernos o de las Fundaciones 
sostenidas por las multinacionales del sector (por ejemplo: «Consecuencias para la distribución minorista de la introducción del videotex», «Previsiones del consumo doméstico de discos ópticos»). Las anteriores observaciones también son de aplicación en España, porque la política del Gobierno socialista apostó por orientar la reconversión tecnológica hacia la incorporación de las «nuevas tecnologías».

Ciertamente que estos estudios de las consecuencias de la introducción de tecnologías comunicativas, centrados en los efectos de mercado, tienen utilidad práctica e incluso interés teórico. Pero existe otro nivel de análisis de los efectos, aquél en el que se relacionan con sus causas, y con sus consecuencias, que en la práctica han dejado de financiarse. Esa desaparición del estímulo «oficial» para el progreso de la teoría básica, también se nota en el giro que han dado los planes de estudio de la comunicación, desde una perspectiva sociológica en la formación de los comunicadores a otra tecnológica.

En este caso, la decisión de reorientar los estudios sobre la comunicación hacia contenidos y usos instrumentales, fue una medida consciente y explícitamente adoptada en primer lugar por los gobiernos de EE.UU. e Inglaterra. Al tiempo que dejaban de financiar a la UNESCO se propusieron yugular el progreso teórico y la popularidad que durante la década de los setenta había alcanzado la Sociología de la Comunicación en los países industrializados; pero sobre todo en el Tercer Mundo. Ha sido una de esas ocasiones en las que luchar con los medios del Estado contra la difusión de la investigación social, se entendió en los países más poderosos como un objetivo de interés nacional. Porque la crítica del dominio económico y cultural de los paises sobre-industrializados sobre los países dependientes, se había centrado precisamente en la denuncia de las nuevas modalidades de expropiación espiritual y material que se facilitan mediante el control de las comunicaciones.

\section{LA DESAPARICION DEL CONTROL DE LOS ESTADOS SOBRE SUS PROPIAS POLITICAS DE COMUNICACION PUBLICA}

Las esperanzas que algunos gobiernos de países dependientes concibieron, de poner la comunicación pública al servicio de «políticas nacionales de comunicación», nunca podía llegar a cumplirse. Porque la producción y la distribución de comunicación pública es ya una actividad que los gobiernos de países dependientes del Imperio, administran por delegación, en aspectos cada vez más limitados.

A tenor de lo que he mostrado en este artículo, la clase de actividad comunicativa que los gobiernos van a poder gestionar en el futuro, al servicio de programas nacionales, se reducirá a aquellas funciones comunicativas en las que se maneje una información que carezca de valor 
de cambio. Y esa clase de productos comunicativos se irán reduciendo progresiva y rápidamente, hasta quedar limitada a las actividades de comunicación pública que sirvan para garantizar el orden social y el funcionamiento de los servicios públicos. Las otras grandes tareas de la comunicación pública, vinculadas a la reproducción social, tales como poner en circulación valores estéticos, lúdicos, cognoscitivos, morales, ciudadanos, van a ser transferidas a unas pocas multinacionales de la producción y de la distribución de información; las cuales representan, en este momento, la punta de lanza de un dominio en el que confluyen y se funden por primera vez en un único proceso, la expropiación económica y cultural de una parte mayoritaria de la humanidad. 